\title{
ĐÔTT PHÁ TRONG MINH GIẢI TÀI LIẸU ĐỊA CHẤN 3D ĐỂ PHÁT HIỆN CÁC BẪY CHỨA ĐỊA TẦNG
}

\author{
Nguyễn Xuân Thịnh', Hà Quang Mẫn² \\ 'Eliis Pty Ltd, Australia \\ ${ }^{2}$ Tổng công ty Thăm dò Khai thác Dầu khí \\ Email: manhq@pvep.com.vn \\ https://doi.org/10.47800/PVJ.2021.03-06
}

\section{Tóm tắt}

Bài báo giới thiệu phương pháp minh giải địa chấn toàn phần (global seismic interpretation method) được phát triển bởi Pauget và nnk. [1]. Mô hình 3D thời gian địa chất tương đối (3D relative geologic time, $R G T)$ được xây dựng trực tiếp từ tài liệu địa chấn là kết quả của phương pháp này. Trong mô hình RGT, tuổi địa chất có sự tiếp diễn liên tục, được nội suy và xác định trên mọi điểm của tài liệu địa chấn 3D.

Tài liệu sử dụng trong nghiên cứu này là khối địa chấn Maui 3D, bể trầm tích Taranaki, ngoài khơi New Zealand. Mô hình RGT với số lượng 400 mặt phản xạ được đưa ra nhanh chóng trong quá trình minh giải. Kết quả cho thấy rõ ràng và chi tiết các đặc điểm địa chất ngay cả với khu vực địa chất phức tạp mà phương pháp minh giải địa chấn truyền thống khó minh giải. Ngoài ra, việc tích hợp các thuộc tính địa chấn (như Root Mean Square - RMS, Spectral Decomposition...) cho phép minh giải chi tiết hơn về địa tầng, chính xác hóa các yếu tố về cấu trúc địa chất, đặc trưng vỉa chứa và môi trường cổ trầm tích, từ đó có thể phát hiện các bẫy chứa địa tầng.

Từ khóa: Minh giải địa chấn, thuộc tính địa chấn, mặt phản xạ, bẫy chứa địa tầng, bể trầm tích Taranaki.

\section{Giới thiệu}

Gần đây, các kỹ thuật minh giải địa chấn đã phát triển nhanh chóng, giúp xác định các cấu tạo địa chất, phát hiện và nghiên cứu đặc trưng của vỉa chứa. Nhìn chung, các phương pháp minh giải truyền thống thường phức tạp và tốn nhiều thời gian, phụ thuộc vào việc minh giải bằng tay một số tầng phản xạ quan trọng. Mặc dù các công cụ liên kết tự động xác định độ tương quan biên độ địa chấn (auto-tracking) là tiến bộ lớn nhưng phương pháp này chỉ có thể tự động minh giải 1 tầng phản xạ/lần và chỉ giới hạn trong khu vực có tín hiệu địa chấn tốt, rõ ràng, hoặc cấu trúc địa chất đơn giản.

Nhiều phương pháp minh giải địa chấn mới đã và đang được giới thiệu để khai thác triệt để tính 3 chiều của dữ liệu và minh giải đồng thời cùng lúc các tầng phản xạ ở trong khối địa chấn 3D [2 - 6]. Năm 2009, Pauget và nnk. đề xuất phương pháp minh giải địa chấn toàn phần, giúp xây dựng mô hình địa chất trực tiếp từ tài liệu địa chấn 3D [1]. Phương pháp giúp tối

Ngày nhận bài:26/10/2020. Ngày phản biện đánh giá và sửa chữa: 26/10/2020 - 4/2/2021. Ngày bài báo được duyệt đăng: 9/3/2021. ưu hóa quy trình minh giải địa chấn với độ chính xác và tin cậy cao hơn. Các mặt địa tầng có tuổi giống nhau ở mọi vị trí có thể được đưa ra trên mọi điểm của tài liệu địa chấn 3D, cho phép khắc phục hạn chế của sự thay đổi pha địa chấn.

Trong nghiên cứu này, nhóm tác giả áp dụng phương pháp minh giải địa chấn toàn phần và tích hợp các thuộc tính địa chấn liên quan như RMS và Spectral Decomposition để làm sáng tỏ hình ảnh các ranh giới địa tầng, làm nổi bật môi trường trầm tích cổ và đặc tính của vỉa chứa trong khối địa chấn Maui 3D.

\section{2. Đối tượng và phương pháp nghiên cứu}

\subsection{Khu vực nghiên cứu}

Taranaki là bể trầm tích lớn nhất ở New Zealand, có diện tích 100.000 km² với độ dày trầm tích Cretaceous-Cenozoic khoảng 10 km (Hình 1). Quá trình tách giãn bắt đầu từ cuối Cretaceous và kết thúc hoàn toàn trong Paleocene, với sự lắng đọng trầm tích nhanh trong các khu vực địa hào, đi cùng với 
dòng nhiệt cao. Trong thời kỳ từ Paleocene đến Eocence, rìa thụ động được hình thành và phát triển trên toàn bộ tiểu lục địa, tốc độ lắng đọng chậm cho phép trầm tích được tích tụ trên khu vực thềm và đồng bằng ven biển trong bể Taranaki [7]. Thời kỳ từ Eocene muộn đến Oligo-

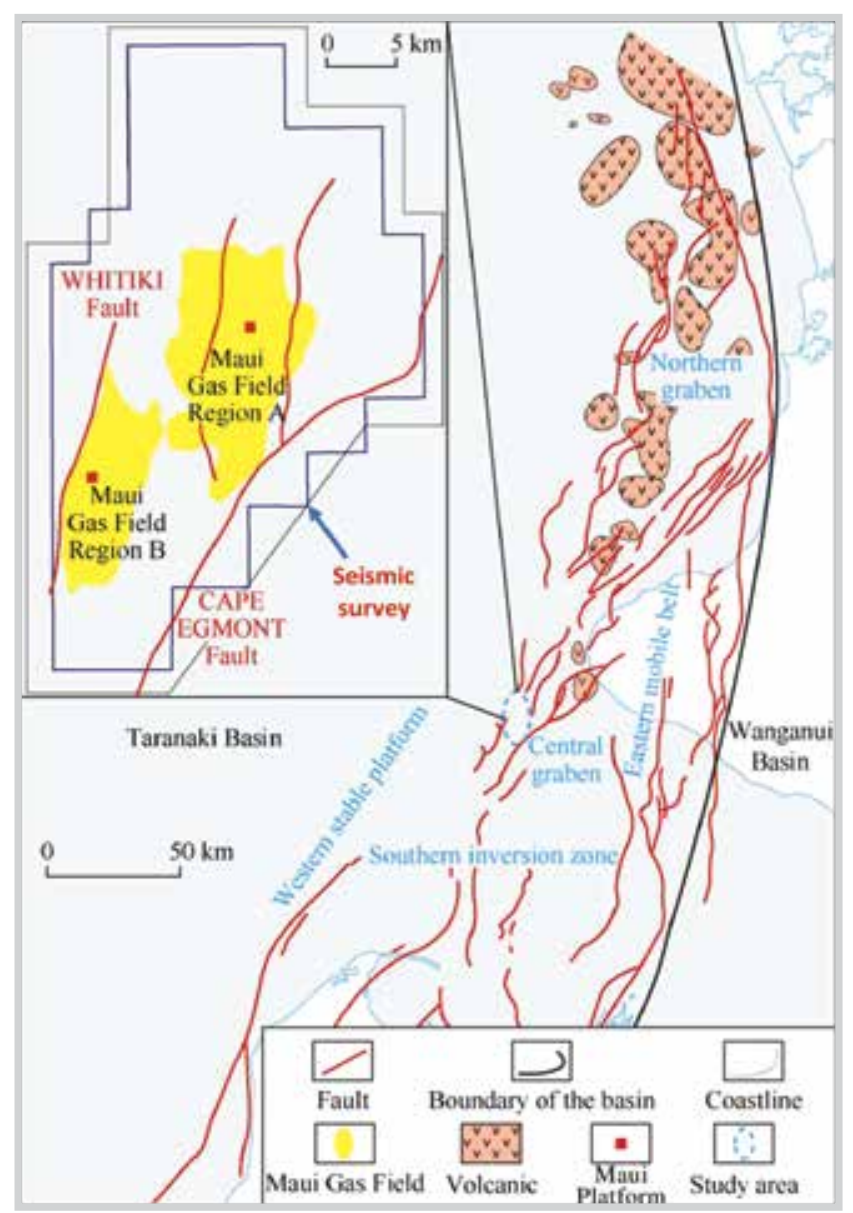

Hình 1. Vị trí của mỏ khí Maui và khu vực khảo sát địa chấn Maui 3D, bể trầm tích Taranaki, New Zealand. Chỉnh sửa từ King và Thrasher (1996), Higgs và nnk. (2012), Haque và nnk. [9].

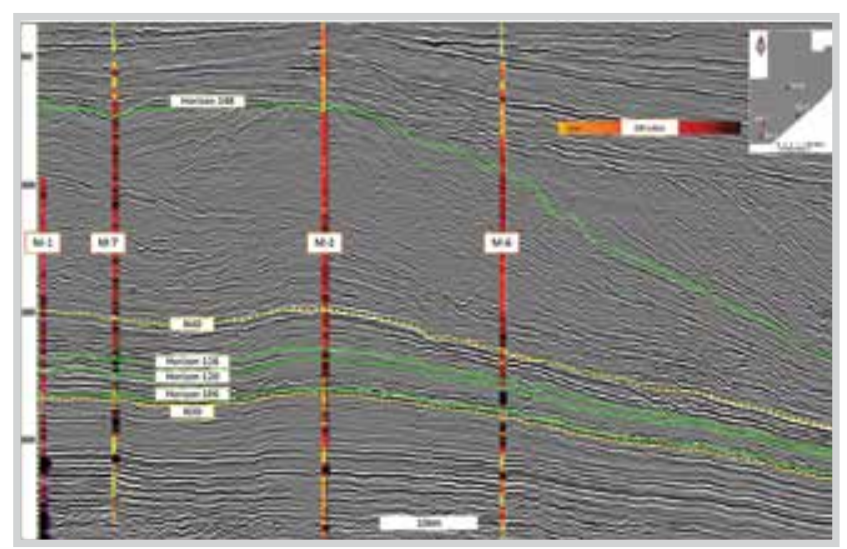

Hình 2. Mặt cắt từ tài liệu địa chấn Maui 3D đi qua các giếng khoan Maui (M) 1, 7, 2, 6 . Đường đứt đoạn màu vàng là những tânng phản xạ N40 và N30 trong Miocene giữa, được minh giải từ Thrasher và nnk. [10]. Các đường màu xanh tương ứng với các mặt phản xạ số 106, 120, 126 và 248 được đưa ra từ tập mặt phản xa - Horizon Stack (Hình 5 - 7). cene sớm đánh dấu sự thiếu hụt trầm tích hạt vụn. Sau đó, bể trầm tích Taranaki trải qua giai đoạn lắng đọng từ Oligocene đến Miocene sớm, gây ra bởi sự phát triển của ranh giới giữa mảng Australia và Thái Bình Dương ở khu vực phía Đông. Tiếp theo là sự phát triển của trầm tích đá vôi và sét vôi ở khu vực ngoài của thềm cho đến phần trên của biển thẳm [8]. Sự gia tăng của vật liệu trầm tích đóng góp vào sự phát triển của hệ thống gờ thềm lục địa trong thời kỳ Miocene, dẫn đến sự lắng đọng của cát kết, sét, bột kết xen kẽ ở khu vực ngoài thềm. Sự phát triển của ranh giới mảng cũng dẫn tới việc tầng móng nghịch chờm lên đứt gãy Taranaki và sự hình thành của khu vực nghịch chờm Tarata trong thời kỳ Miocene sớm. Cho đến giữa thời kỳ Miocene, sự nén ép lên khu vực phía Bắc và rìa phía Đông của bể đã giảm xuống, đồng thời với sự phát triển của vòng cung núi lửa dưới đáy biển. Trong suốt thời kỳ Pliocene, vòng cung núi lửa dịch chuyển về phía Đông Nam vào bờ và khu vực phía Bắc của bể Taranaki bắt đầu mở rộng, tạo không gian cho sự tiến triển của đường bờ trong khoảng Pliocene - Pleistocene và sự bồi tụ trầm tích của hệ tầng Giant Foresets ở khu vực địa hào phía Bắc và trung tâm của bể Taranaki.

\subsection{Tài liệu địa chấn 3D Maui}

Tài liệu địa chấn 3D Maui có diện tích rộng khoảng 1.000 km² (Hình 1) được sử dụng trong nghiên cứu này là tài liệu xử lý dịch chuyển theo miền thời gian sau khi cộng. Tài liệu địa chấn đã được xử lý ở pha 0 (zero phase), trong đó sự gia tăng trở kháng âm học được hiển thị bằng biên độ dương (phản xạ đỉnh) và sự giảm trở kháng âm học được hiển thị bằng biên độ âm (phản xạ đáy) ở trên mặt cắt địa chấn (Hình 2 ). Khảo sát địa chấn $3 \mathrm{D}$ được thực hiện với bin size $25 \times 25$ m, 1.836 mẫu/xung, bước lấy mẫu $3 \mathrm{~ms}$ và thời gian ghi là $5.600 \mathrm{~ms}$. Trong khu vực khảo sát địa chấn này, mỏ khí Maui với 17 giếng khoan thăm dò và khai thác là một trong những mỏ khí condensate lớn nhất New Zealand (Hình 1).

\subsection{Phương pháp minh giải địa chấn toàn phần}

Các phương pháp minh giải địa chấn truyền thống gồm minh giải bằng tay (manually-picking) hoặc minh giải tự động (auto-tracking) các tầng phản xạ chính trong khối địa chấn là quá trình tốn nhiều thời gian và công sức. Việc minh giải chi tiết hàng trăm mặt phản xạ (horizon) trong khối địa chấn 3D có diện tích hàng nghìn km², với độ tin cậy cao chỉ trong thời gian ngắn là khó khả thi với phương pháp minh giải truyền thống.

Để giải quyết vấn đề này, Pauget và nnk. [1] đã nghiên 


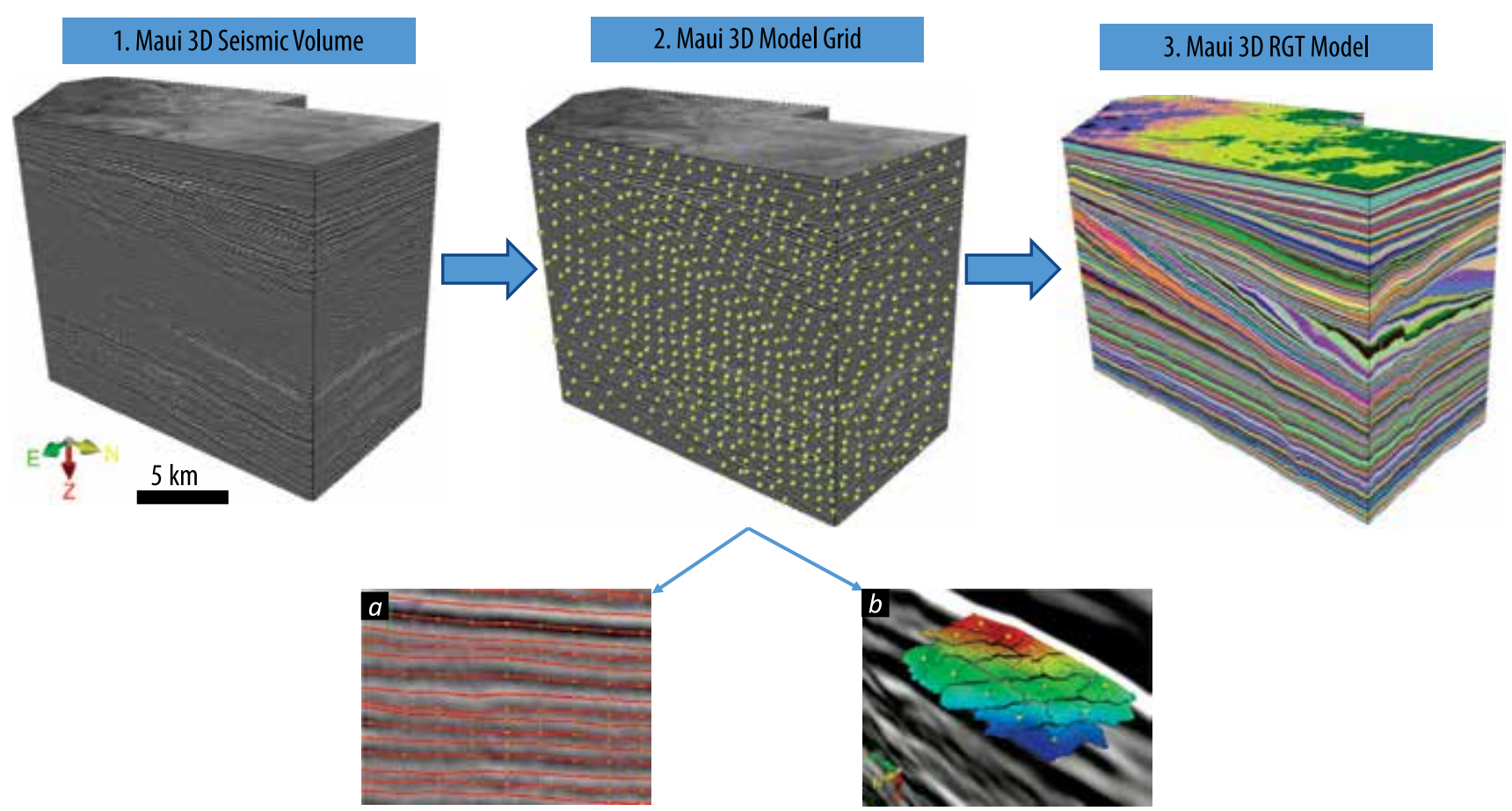

Hinh 3. Tóm tắt quy trình minh giải: (1) khối địa chấn Maui 3D, (2) 3D Model Grid được xây dựng, trong đó, toàn bộ các tầng phản xạ trong khối địa chấn được minh giải tư động cùng một lúc dựa vào độ tương quan của xung địa chấn, khi các điểm lưới màu vàng được kết nối lại trong 2D (a) và 3D (b), (3) Mô hình địa chất Maui - 3D RGT model là kết quả của việc nội suy 3D Model Grid.

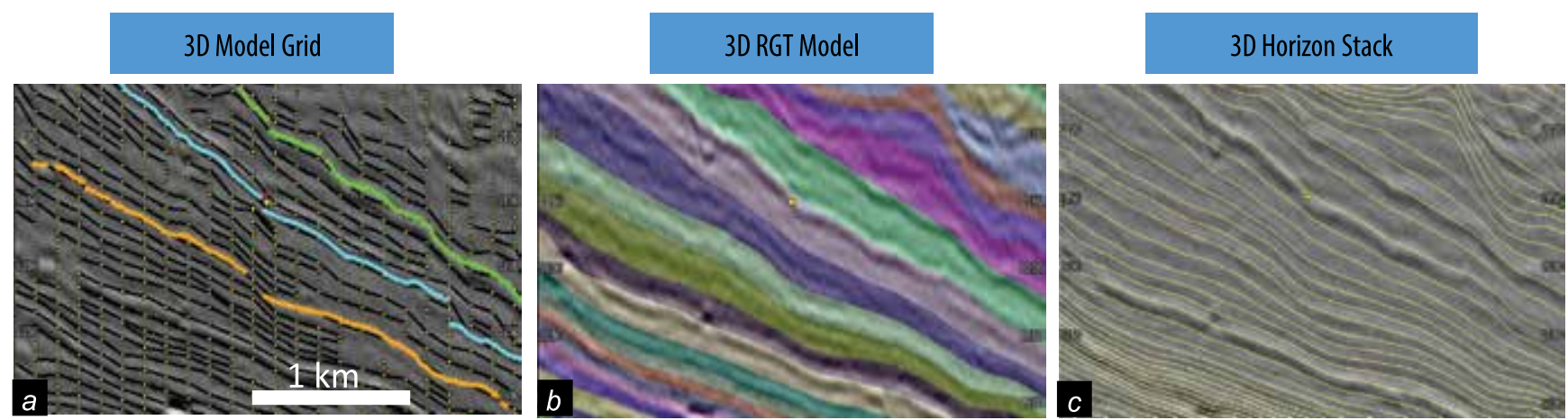

Hình 4. (a) 3D Model Grid, trong đó người minh giải có thể tinh chỉnh, sắp xếp theo ý muốn các tânng phản xạ đã được minh giải tự động. (b) Mặt cắt trong mô hình địa chất RGT, chỉ ra sự ảnh hưởng của tướng địa chấn lên trên tướng địa chất trong mô hình. Thay vi có giá trị biên độ, các giá trị tuổi địa chất tương đối được chỉ định trong mô hình RGT. (c) Tập mặt phản xạ bao gồm các bề mặt địa tâng dày đặc tương ứng với giá trị tuổi địa chất tương đối trong mô hình RGT.

cứu ứng dụng phương pháp minh giải địa chấn mới, dựa trên thuật toán học máy (machine learning) có tên là “Cost function minimisation", bao gồm 2 bước chính sau:

- Bước 1: Mạng lưới tầng phản xạ - 3D Model Grid (MDG) xây dựng trực tiếp từ khối địa chấn 3D, chứa hàng triệu mảng phản xạ sơ cấp (Hình 3). Điều này được thực hiện dựa trên hàng triệu điểm lưới được phân bố trong khối địa chấn 3D, trên các pha của xung địa chấn như: peaks, troughs, zero crossings hoặc inflection points với khoảng cách không đổi dựa trên bin size của tài liệu địa chấn (Hình 3a). Ví dụ, có thể phân bố các điểm lưới lên trên toàn bộ pha peak và trough của xung địa chấn, và cứ 3 xung địa chấn sẽ có 1 điểm lưới, qua đó có được độ phân giải dọc của MDG.
- Bước 2: Mỗi điểm lưới sẽ đại diện cho mảng phản xạ sơ cấp trong 3D, diện tích có thể điều chỉnh theo bin size của địa chấn, giúp xác định độ phân giải ngang của MDG (Hình 3b).

Sử dụng thuật toán trên [1], các mảng phản xạ sơ cấp được kết nối dựa vào độ tương quan của xung địa chấn như: tần số, biên độ và khoảng cách trong không gian 3 chiều. Ví dụ, 2 cực của 2 xung địa chấn cách nhau 3 bin size có độ tương quan 30\%, 2 điểm lưới đặt trên 2 cực đó sẽ được liên kết, đồng nghĩa với 2 mảng phản xạ sơ cấp tương ứng với 2 điểm lưới đó cũng sẽ được kết nối lại, tạo ra một mảng phản xạ lớn hơn. Với quá trình liên kết này, cùng lúc tất cả tầng phản xạ có thể có trong khối địa 
chấn 3D sẽ được tự động minh giải (Hình 3a và b), làm bộ khung cho mô hình địa chất sau này.

Thực tế khi 2 mảng phản xạ sơ cấp được kết nối, sẽ được chỉ định có cùng "tuổi địa chất tương đối". Vì vậy, tất cả tầng phản xạ được minh giải cùng lúc sẽ được sắp xếp theo thứ tự địa tầng, không bao giờ cắt hoặc trùng nhau nhờ thuật toán nâng cao.

Trong bước thứ 2, mô hình thời gian địa chất tương đối - 3D Relative Geologic Time model - được tính toán từ việc nội suy mạng lưới MDG, trong đó, tuổi địa chất tương đối sẽ mang tính liên tục và được chỉ định cho mọi điểm của khối địa chấn 3D. Vai trò của người minh giải địa chấn sẽ là tinh chỉnh và sắp xếp lại các tầng phản xạ được đưa ra tự động trong MDG theo ý tưởng phù hợp nhất với mô hình địa chất của khu vực nghiên cứu (Hình 3).

\subsection{Tập mặt phản xạ}

Từ mô hình địa chất RGT, tập mặt phản xạ (horizon stack) bao gồm không giới hạn các bề mặt phân cách địa tầng và trên mỗi bề mặt sẽ có tuổi giống nhau ở mọi vị trí, có thể được đưa ra để xác định rõ hơn các yếu tố và hiện tượng địa chất ở độ phân giải rất cao. Các mặt phản xạ này chỉ cách nhau từ 5 - 7 ms (Hình 4) và khác biệt hoàn toàn so với các mặt cắt ngang (time slices) trong khối địa chấn 3D. Thuộc tính địa chấn có thể được tính toán nhanh và đưa ra ngay trên các mặt phản xạ, như thuộc tính RMS, Spectral Decomposition... Những thuộc tính trên được tính toán trong khoảng cửa sổ cố định (theo số lượng mẫu) cho mỗi mặt phản xạ đã minh giải. Ví dụ, cửa sổ thuộc tính là 5 mẫu trong trường hợp khoảng lấy mẫu dọc của tài liệu địa chấn là 4 ms nghĩa là cửa sổ thuộc tính có độ lớn 20 ms, thuộc tính sẽ được tính toán và đưa ra theo cửa sổ +/- 10ms của mỗi mặt phản xạ trong tập mặt phản xạ . Phương pháp này đã được áp dụng thành công trong nhiều công trình nghiên cứu, khoanh vùng được các bẫy dầu khí dạng địa tầng với thân vỉa mỏng, cũng như làm rõ hơn hình ảnh của môi trường trầm tích cổ, đứt gãy và các đới dập vỡ [5, 11 - 13].

\section{Kết quả và thảo luận}

Sử dụng phần mềm PaleoScan ${ }^{\mathrm{TM}}$, tất cả tầng phản xạ đã được minh giải tự động cùng lúc, theo các pha peak, trough, zero-crossing, giảm thiểu tối đa thời gian so với các phương pháp minh giải truyền thống. Kết quả thu được là mô hình địa chất RGT, được xây dựng trực tiếp từ khối địa chấn Maui 3D. Trong quy trình minh giải, bước nội suy MDG đóng vai trò quan trọng nhất, chỉ định tuổi

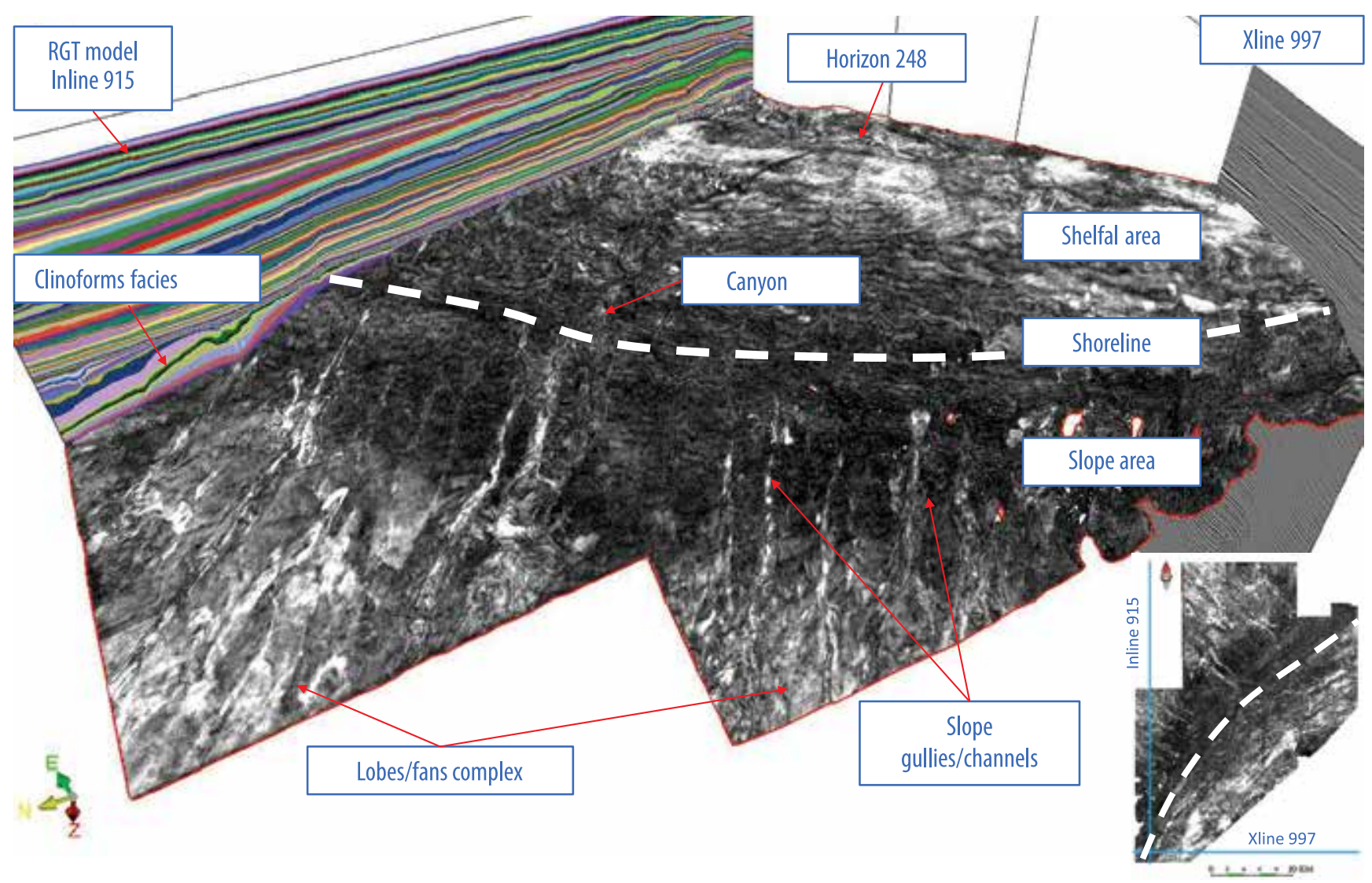

Hình 5. Mặt phản xạ 248 với thuộc tính địa chấn RMS chỉ ra các thông tin, hiện tượng địa chất trong môi trường biển nông được hiển thị một cách chi tiết (vị trí mặt cắt chỉ ra trên Hinh 2). 


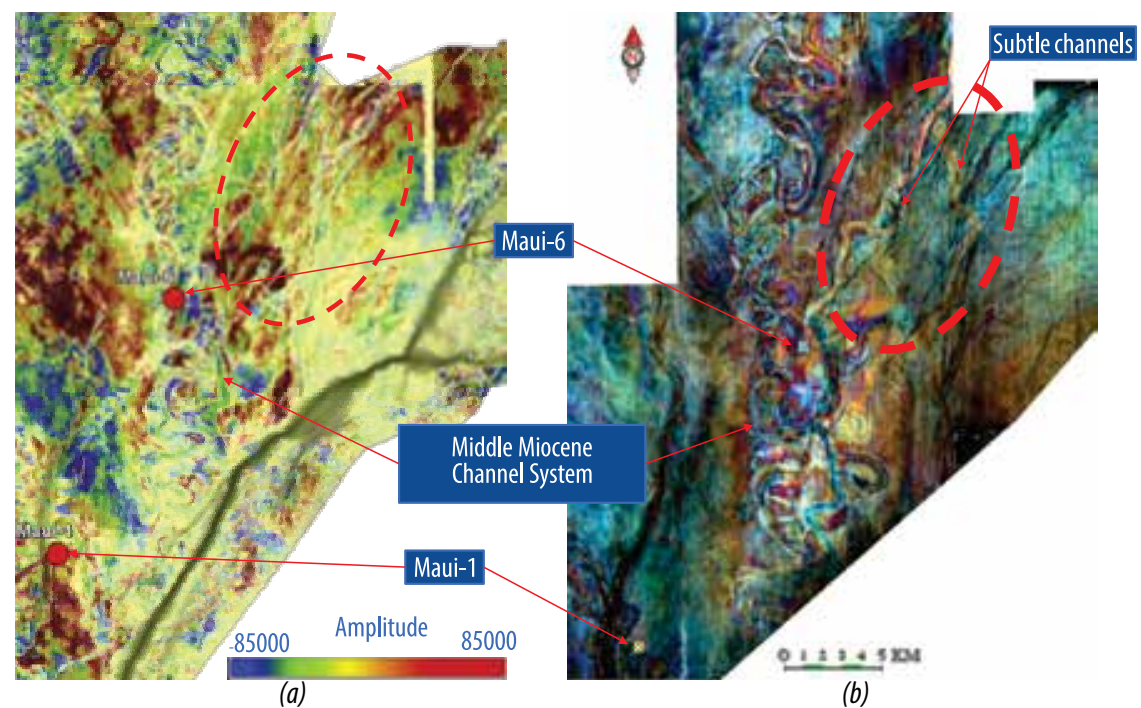

Hình 6. So sánh giữa mặt phản xạ được tính trong khoảng giũa N30 - N40, sử dụng phương pháp truyền thống (Iso-proportional slicing) của tác giả Kroeger et al. [14] (a) và mặt phản xạ số 106 trong tập mặt phản xạ với thuộc tính địa chấn Spectral Decomposition cho 3 tần số khác nhau được pha trộn cùng lúc (b).
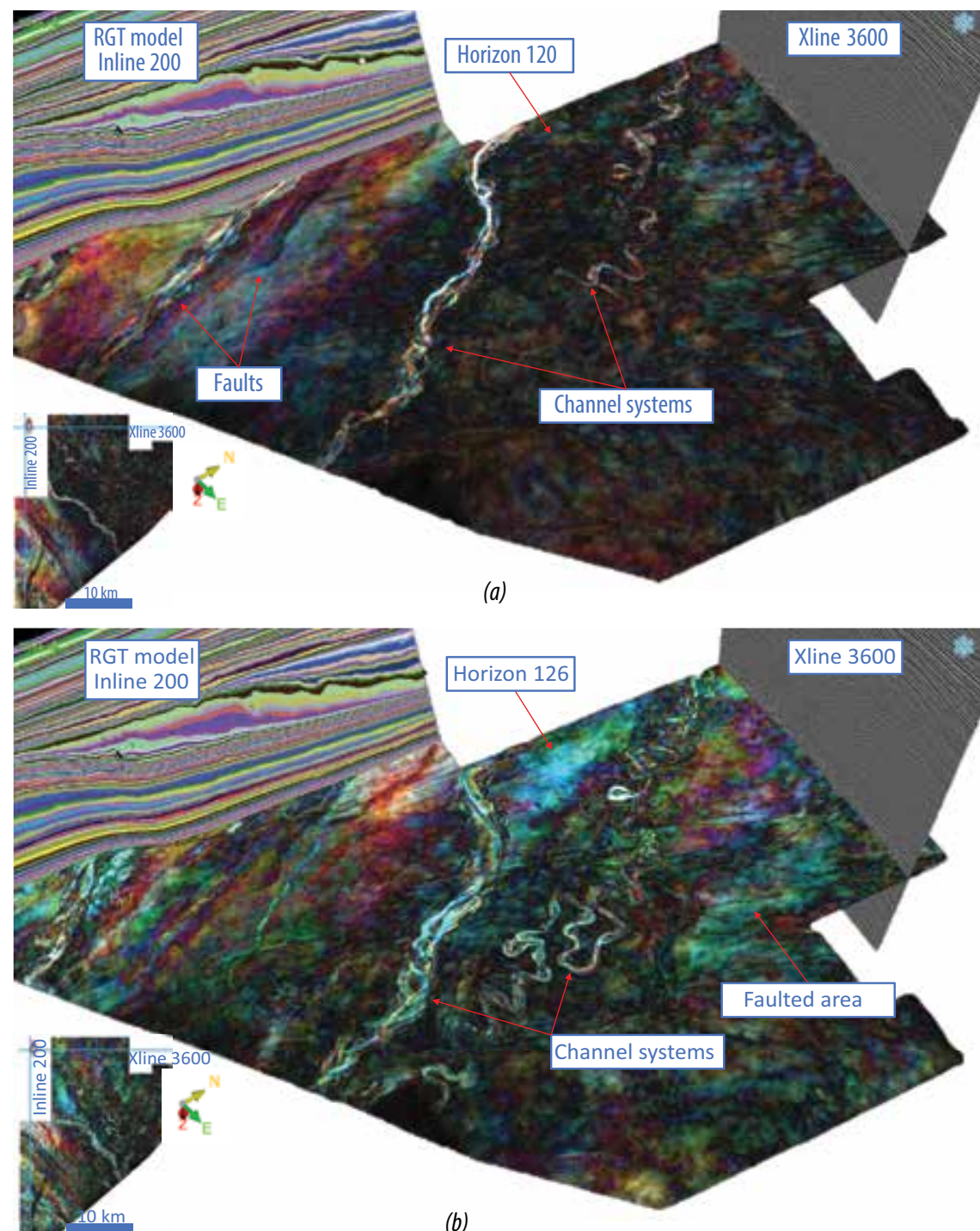

Hình 7. Sử dụng thuộc tính địa chấn Spectral Decomposition với 3 tần số khác nhau để làm rõ hơn sự phát triển của hê thống dòng sông cổ tuổi Miocene giũa trên mặt cắt 120 (a) và 126 (b) trong tập mặt phản xạ. đia chất tương đối cho mọi điểm của khối địa chấn dựa trên những tầng phản xạ đã được minh giải tự động, tạo nên sự liên tục về tuổi địa chất theo không gian và thời gian trong mô hình RGT.

Trong nghiên cứu này, 400 mặt phản xạ tương ứng với tuổi địa chất tương đối được đưa ra từ mô hình RGT. Kỹ thuật minh giải cho phép điều hướng khối địa chấn 3D theo các mặt phản xạ, đưa ra các thông tin nội tầng với độ phân giải rất cao, ngay cả với khu vực cấu trúc địa chất phức tạp hoặc trong môi trường trầm tích phức tạp như trầm tích biển nông, trầm tích rìa hoặc biển sâu (Hình 5) mà phương pháp minh giải truyền thống khó phát hiện được.

Trong các phương pháp minh giải địa chấn truyền thống, thuộc tính địa chấn thường được đưa ra trên mặt cắt thời gian, hoặc trên các mặt phản xạ quan trọng hoặc các ranh giới khác được dịch chuyển song song với những tầng phản xạ quan trọng đó. Phương pháp này mất nhiều thời gian và khó có thể đưa ra chi tiết về đặc điểm đia chất khu vực nhất là khu vực có địa chất phức tạp, khi các mặt cắt trong nội tầng không đi theo đúng hình dạng những mặt phản xạ. Ở nghiên cứu này, trong khoảng thời gian ngắn, hàng trăm thậm chí hàng nghìn mặt phản xạ theo địa tầng có thể được đưa ra từ mô hình địa chất RGT và cho mọi điểm trong khối địa chấn 3D. Ngoài ra, khác biệt với phương pháp iso-proportional slicing (các mặt cắt nội tầng được tạo ra khi chia đều tầng địa chất theo tầng phản xạ giới hạn đỉnh và đáy), tập mặt phản xạ đưa ra các mặt phản xạ, trong đó trên mỗi mặt phản xạ có tuổi địa chất tương đối theo địa tầng, thường liên tục từ trên xuống dưới 
và đồng tuổi theo diện phân bố ở mọi vị trí. Các bề mặt phản xạ này có thể được chỉ ra trong những tầng địa chất phức tạp, nhưng vẫn tuân theo tướng địa chấn, là những tầng phản xạ được minh giải tự động trong MDG, do đó hiển thị tốt hơn và khai thác thông tin tối đa từ tài liệu địa chấn 3D (Hình 6).

Phương pháp này giúp minh giải địa chấn hiệu quả hơn, xác định được mô hình địa chất hoàn toàn nhất quán với tài liệu địa chấn $3 \mathrm{D}$, cùng với các mặt phản xạ, hiển thị đứt gãy với độ chính xác cao để phục vụ cho bước kế tiếp như mô hình hóa cấu trúc địa chất, mô hình tướng... (Hình 6 và 7).

\section{Kết luận}

Trong nghiên cứu này, một kỹ thuật minh giải mới được giới thiệu và áp dụng lên tài liệu địa chấn $3 \mathrm{D}$ để từ đó xây dựng trực tiếp mô hình 3D tuổi địa chất tương đối RGT. Phương pháp này cho phép đưa ra không giới hạn số lượng mặt phản xạ trong những tầng địa chất phức tạp theo thứ tự địa tầng, giúp làm nổi bật hơn các thông tin, yếu tố, hiện tượng địa chất quan trọng không thể nhìn thấy được khi sử dụng các phương pháp minh giải địa chấn truyền thống có số lượng giới hạn mặt phản xạ được minh giải.

Từ tài liệu địa chấn Maui 3D, bể trầm tích Taranaki, ngoài khơi New Zealand, mô hình địa chất RGT đã được xây dựng trong khoảng thời gian ngắn, giúp minh giải 400 mặt phản xạ. Những mặt phản xạ đó được kết hợp với các thuộc tính địa chấn như Root Mean Square - RMS và Spectral Decomposition giúp cho người minh giải xây dựng lịch sử phát triển, kiến tạo địa chất trong khu vực nghiên cứu. Kết quả minh giải có thể áp dụng trong các bước tiếp theo như xây dựng mô hình cấu trúc địa chất cho khu vực nói chung và mỏ nói riêng. Việc phân chia các lớp (layer) trong mô hình cũng tiệm cận hơn với mô hình địa chất... Quy trình minh giải địa chấn này tiết kiệm công sức và rút ngắn thời gian, từ đó giúp đẩy nhanh toàn bộ quá trình tìm kiếm thăm dò dầu khí, định hình một phương pháp minh giải địa chấn mới trong tương lai.

\section{Lời cảm ơn}

Kết quả trong nghiên cứu này đạt được từ phần mềm minh giải địa chấn PaleoScan ${ }^{\mathrm{TM}}$, phát triển bởi Eliis (www. eliis.fr). Nhóm tác giả gửi lời cảm ơn đến Ministry of Business, Innovation, and Employment (MBIE), New Zealand, đã cho phép công bố tài liệu địa chấn Maui 3D và anh Nguyễn Tiến Thịnh - Viện Dầu khí Việt Nam, đã góp ý giúp tác giả hoàn thiện nghiên cứu này.

\section{Tài liệu tham khảo}

[1] Fabien Pauget, Sébastien Lacaze, and Thomas Valding,"A global approach to seismic interpretation based on cost function and minimization", SEG Technical Program Expanded Abstracts 2009. DOI: 10.1190/1.3255384.

[2] Hilde G. Borgos, Thorleif Skov, Trygve Randen, and Lars Sonneland, "Automated geometry extraction from 3D seismic data", SEG Technical Program Expanded Abstracts 2003. DOI: 10.1190/1.1817590

[3] Paul de Groot, Arnaud Huck, Geert de Bruin, Nanne Hemstra, and Jonathan Bedford, "The horizon cube: A step change in seismic interpretation", The Leading Edge, Vol. 29, No. 9, pp. 1048 - 1055, 2010. DOI: 10.1190/1.3485765.

[4] H.J. Ligtenberg, G. de Bruin, N. Hemstra, and C. Geel, "Sequence stratigraphic interpretation in the wheeler transformed (flattened) seismic domain", $68^{\text {th }}$ EAGE Conference and Exhibition Incorporating SPE EUROPEC 2006. DOI: 10.3997/2214-4609.201402337.

[5] Jesse Lomask, Antoine Guitton, Sergey Fomel, Jon Claerbout, and Alejandro A. Valenciano, "Flattening without picking", Geophysics, Vol. 71, pp. 13 - 20, 2006. DOI: 10.1190/1.2210848.

[6] Ingelise Schmidt, Sebastien Lacaze, and Gaynor Paton, "Spectral decomposition and geomodel Interpretation - Combining advanced technologies to create new workflows", $75^{\text {th }}$ EAGE Conference \& Exhibition Incorporating SPE EUROPEC 2013, London, UK, 10 - 13 June 2013. DOI: $10.3997 / 2214-4609.20130567$.

[7] Peter R. King, "Tectonic reconstructions of New Zealand: $40 \mathrm{Ma}$ to the present", New Zealand Journal of Geology and Geophysics, Vol. 43, pp. 611 - 638, 2000. DOI: 10.1080/00288306.2000.9514913.

[8] P.R. King and Glenn P. Thrasher, "CretaceousCenozoic geology and petroleum systems of the Taranaki basin, New Zealand", Institute of geological and nuclear sciences, Vol. 13, No. 2, 1996.

[9] Eahsanul Haque, Aminul Islam, and Mohamed Ragab Shalaby, "Structural modeling of the Maui gas field, Taranaki basin, New Zealand", Journal of Petroleum Exploration and Production Technology, Vol. 43, No. 6, pp. 965 - 975, 2016. DOI: 10.1016/S1876-3804(16)30114-8.

[10] Tracy J. Stark, "Relative geologic time (age) volumes - Relating every seismic sample to a geologically reasonable horizon", The Leading Edge, Vol. 23, No. 9, pp. 928 - 932, 2004. DOI: 10.1190/1.1803505. 
[11] Marco Fonnesu, Denis Palermo, Mauro Galbiati, Marco Marchesini, Enrico Bonamini, and Daniel Bendias, "A new world-class deep-water play-type, deposited by the syndepositional interaction of turbidity flows and bottom currents: The giant Eocene Coral field in northern Mozambique", Marine and Petroleum Geology, Vol. 111, pp. 179 - 201, 2020. DOI: 10.1016/j. marpetgeo.2019.07.047Ge.

[12] Tony Marsh and Anne Powell, "Regional stratal slice imaging of the Northern Carnarvon basin, Western Australia", ASEG Extended Abstracts, 2019. DOI: 10.1080/22020586.2019.12073062.

[13] G. Thrasher, H. Seebeck, P. Viskovic, S. Bull, M. Sarma, and K. Kroeger, "Time structure grids for the greater Maui-Maari-Tui region, Taranaki basin, New Zealand", GNS Science Data Series, 2018.
[14] Karsten F. Kroeger, Glenn P. Thrasher, and Monmoyuri Sarma, "The evolution of a Middle Miocene deep-water sedimentary system in northwestern New Zealand (Taranaki basin): Depositional controls and mechanisms", Marine and Petroleum Geology, Vol. 101, pp.355-372,2019.DOI:10.1016/j.marpetgeo.2018.11.052.

[15] Lia Turrini, Christopher A-L. Jackson, and Philip Thompson, "Seal rock deformation by polygonal faulting, offshore Uruguay", Marine and Petroleum Geology, Vol. 86, pp.892-907,2017.DOI:10.1016/j.marpetgeo.2017.06.038.

[16] Xinming Wu and Dave Hale, "Horizon volumes with interpreted constraints", Geophysics, Vol. 80, No. 2, 2015. DOI: 10.1190/geo2014-0212.1.

\title{
A BREAKTHROUGH IN 3D SEISMIC INTERPRETATION FOR STRATIGRAPHIC RESERVOIR DETECTION
}

\author{
Nguyen Xuan Thinh', Ha Quang Man² \\ 'Eliis Pty Ltd, Australia \\ 2Petrovietnam Exploration Production Corporation (PVEP) \\ Email: manhq@pvep.com.vn
}

\section{Summary}

The paper presents the "global seismic interpretation method", developed by Pauget et al. [1]. A 3D Relative Geologic Time (RGT) model was obtained directly from the 3D seismic volume which is the outcome of this method. In the 3D RGT model, the geologic time is continuous, and a relative geologic age can be interpolated and assigned for to every voxel of the seismic volume.

The dataset in this study is the Maui 3D seismic volume from Taranaki Basin, offshore New Zealand. A stack of four hundred continuous stratigraphic horizons was quickly produced from the Maui RGT model, showing clearly and in detail the geological features of even complicated areas where classical methods failed to achieve good results. Besides, integrated with seismic attributes such as RMS amplitude and/or Spectral Decomposition, the horizon stack enables identification of geological elements, stratigraphic insights, and paleo-depositional environments in greater detail for stratigraphic reservoir detection and characterisation.

Key words: Seismic interpretation, seismic attributes, horizon, stratigraphic reservoir, Taranaki basin. 